\title{
GLOBALIZACIÓN Y TERRITORIO, UN REPLANTEAMIENTO DE LOS DERECHOS CIUDADANOS ${ }^{\prime}$
}

\section{GLOBALIZATION AND TERRITORY, A NEW TREATMENT OF THE CITIZENSHIP RIGHTS}

JORDI BORJA S.

Director.

Urban Technology Consulting S. L de Barcelona

Palabras clave: ciudad, civismo, globalización, intercambio, territorio, espacio público, ciudadano

Key words: town, civic sense, globalization, exchange, territory, public space, citizen.

\section{Resumen}

La ciudad actual, la ciudad de la $3^{\circ}$ revolución, esta hecha de superposiciones, de múltiples situaciones. La ciudad que hemos forjado en nuestro imaginario y consolidado como un valor y una conquista es un producto físico, político y culturalmente complejo, europeo y mediterráneo, americano y asiático, caracterizado como concentración de población y de actividades. Un lugar que propicia la mezcla social y funcional, con capacidad de autogobierno y que es ámbito de identificación simbólica y de participación civica. Ciudad como lugar de encuentro, de intercambio. Ciudad como cultura y comercio. Ciudad de lugares y no únicamente espacio de flujos.

La presión de la dispersión, la segregación y la segmentación del área urbana que se presenta como un magma indefinido nos obliga a redefinir los espacios públicos urbanos en las áreas de
1.Este es el titulo del próximo libro del Dr. Jardi Borja S. El capitulo que, gentilmente, nos ofrece para publicar en esta edición de Anfora, trata sobre Globalización y territorio, un replanteamiento de la ciudad como espacio público. (N de ios E) 
nuevos crecimientos.

Este ensayo trabaja las tres grandes etapas o edades de la ciudad. La primera, de la ciudad concentrada, separada de su entorno. La segunda, la de la ciudad metropolitana, ciudad más periferia. $Y$, la tercera que es la ciudad actual, la de la ciudad "a repensar" en la globalización. La ciudad-región, la ciudad-red, multipolar o policéntrica, inserta en sistemas urbanos macro-regionales, ejes continentales y flujos globales.

\section{Abstract}

The town that exists today, a town of third revolution, is made of overlapping layers, of multiple situations. The town that we have forged in our imagination and consolidated as a value and a conquest, it is a physical product, politically and culturally complex, European and Mediterranean, American and Asiatic, characterized by a concentration of population and activities. A place that fosters social and functional mixtures, with the capability of being self-governed and that it is an environment of symbolic identification and citizenship participation. Town as a meeting place, as an exchange place. A town identified as culture and commerce. Town of places and not only of flux spaces.

The pressure of dispersion, segregation and segmentation of the urban area that presents itself as an undefined magma, forces us to redefine the urban public spaces in the areas of new growth.

This essay works the three main stages or ages of the town. The first one, that of the concentrated, separated from its atmosphere. The second one, that of the metropolitan town, town plus suburbs. And third, that is the modern town, that of the town "to be thought" in the globalization. The town-region, the town-web, multipolar or polycentric, inserted in macro-regional urban systems, continental axis and global fluxes. 


\section{La ciudad es el espacio público.}

Ya hemos señalado que los egipcios representaban la ciudad con un circula y una cruz. El circulo era el lugar, es decir, la comunidad de personas, la organización politica y la identidad cultural. La cruz simbolizaba los flujos, o sea el intercambio de bienes, servicios e informaciones, las movilidades, las relaciones con el exterior. En el espacio público se realiza la sintesis de lugares y flujos. Y la ciudad es el espacio púbilico, lugar de la cohesión social y de los intercambios.

Si un lugar puede definirse como espacio de identidad, relacional e histórico, un espacio que no pueda definirse ni como espacio de identidad ni como relacional ni como histórico, definirá un no lugar... un mundo asi prometido a la individualidad solitaria, a lo efimero, al pasaje... [1]

Decir que la ciudad es la gente es ya un tópico, una expresión atribuida entre otros a Sófocles, Shakespeare y Goethe. $Y$ en este caso gente no sólo quiere decir tamaño y densidad, es decir una concentración más o menos grande de personas, sino que también diversidad, heterogeneidad, relación entre individuos y colectivos diferentes. Aristóteles, en su texto "La Política" ya defendia que la ciudad debe estar compuesta por diferentes clases de personas, que no existe la ciudad si la población se asemeja mucho, como explica Sennet, [2]

Louis Wirth [3] en su texto clásico "Urbanismo como forma de vida", sostenia que: "La ciudad se caracteriza por la heterogeneidad social". La filosofia y la sociologia urbana coinciden en enfatizar que la ciudad es el lugar donde se concentran y conviven las diferencias de origen, de aptitudes, de actividades, admitiendo también que esta diversidad favorece lo imprevisible, introduce desorden y posibilita la innovación [4] - La diversidad, con la condición de un mínimo de pautas comunes civismo- que posibilitan la convivencia, hace posible el intercambio. Y tanto el civismo como el intercambio de productos, servicios e ideasnecesitan, se desarrollan y se expresan en el espacio público.

Según Habermas [5], la ciudad es especialmente el espacio público 
donde el poder se hace visible, donde la sociedad se fotografia, donde el simbolismo colectivo se materializa, O como decia Henri Lefebvre [6], en su libro "Le droit à la Ville", "La ciudad es la sociedad inscripta en el suelo [...]". La ciudad es un escenario, un espacio público que cuanto más abierto sea a todos, más expresará la democratización politica y social. En consecuencia las dinámicas privatizadoras del espacio urbano, sobre las que algunos autores citados nos advierten socavan fa concepción de la cludad como ámbito de la ciudadanía.

Ciudadania que implica el reconocimiento de los ciudadanos como sujetos activos e iguales de la comunidad política, a los que se reconoce el derecho y la posibilidad real de acceder a la diversidad de las ofertas urbanas. La ciudad y su espacio público es el lugar de la representación y expresión de la sociedad, tanto de dominados como de dominantes. El espacio público como dice Pietro Barcellona es también donde la sociedad desigual y contradictoria puede expresar sus conflictos.

En la ciudad posmoderna y de los flujos, el lugar y su referencia a la comunidad es sustituido por el espacio del consumo.

No hay ya espacios creados por una comunidad [...] sino itinerarios individuales, imprevisibles aleatorios, trazados por el hiperconsumo, que son propiedad del individuo y no de la sociedad. [...] el individuo moderno no se ha puesto en movimiento en busca de un lugar distinto a aquel al que pertenece. Ya no hay lugares: con la destrucción del espacio de la polis se ha perdido para siempre un orden politico, ético y social. [7]

El sujeto ciudadano nace ("las personas nacen libres e iguales" prociamaban las revoluciones americana y francesa a finales del siglo XVIII) y también se hace: ejerciendo o reclamando sus derechos de libertad e igualdad.

"Ayer, en la manifestación de desempleados, atravesando la ciudad, me senti, por primera vez en muchos años, un ciudadano", declaraba un manifestante en París en mayo de 1997. Precisamente es la expresión del conflicto la que permite sentirse ciudadano, y la ciudad como lugar de representación, es también espacio del cambio político

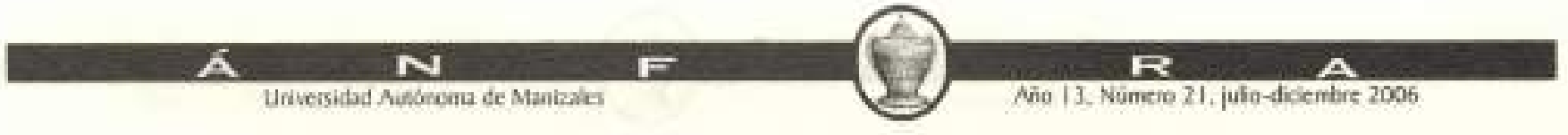


y de la trasgresión.

En el tiempo del consumo, todas las reivindicaciones, los deseos son negociables, porque un conflicto que señala objetivos reales y materiales siempre es negociable [...]

Para el individuo metropolitano la producción de sentido parte de aquí: cuando el consumo se convierte en una propiedad exclusiva suya con la que comunica, realiza su status, escoge sus ciudadanias. Pero solo por un momento [B]

En el espacio público como escenario de representación la sociedad adquiere visibilidad. A partir del ágora o la plaza de las manifestaciones políticas multitudinarias del siglo $X X$ se puede relatar y comprender la historia de una ciudad. Estampas gloriosas y trágicas, antiguas y modernas, se suceden en los espacios públicos de las ciudades. Es suficiente con recordar lugares y momentos históricos como las manifestaciones en París iniciadas en la República o en la Bastilla, las plazas de las Tres Culturas en México o Tiananmen en Pekin. O la reacción en Barcelona y otras ciudades de España ante la arrogancia del entonces ministro Manuel Fraga cuando dijo que "la calle es mía". O los "cacerolazos", los "que se vayan todos" (Buenos Aires) de las ciudades latinoamericanas en las que el descontento popular toma las calles.

También el espacio público se hace ciudadano cuando deviene lugar de expresión a través de la flesta de las diferencias y de las elecciones como los desfiles del dia del orgullo gay que toman las calles de Nueva York y San Francisco entre otras; o la expresión popular de los carnavales de Rio de Janeiro o Venecia. Fiestas, reclamos o protestas, en tanto que manifestaciones de ciudadania solo son posibles en el espacio público.

\section{El espacio público en la modernidad.}

El espacio público como concepto juridico es un espacio sometido a una regulación especifica por parte de la administración pública, propietaria o que posee la facultad de dominio sobre el suelo y que 
garantiza la accesibilidad a todos y fija las condiciones de utilización y de instalación de actividades. El espacio público moderno resulta de la separación formal (legal) entre la propiedad privada urbana (expresada en el catastro y vinculada generalmente al derecho a edificar) y la propiedad pública (o dominio público por subrogación normativa o por adquisición de derechos por medio de la cesión).

El espacio público, o su calificación como tal, suponen reservar este suelo libre de construcción permanente para el uso comunitario o destinado a equipamientos colectivos de interés general (equipamientos sociales y culturales) o infraestructuras de movilidad. Asimismo puede destinarse a usos efimeros de carácter culturai o comercial, a la instalación de referencias simbólicas monumentales y a espacios de reserva para usos intermitentes o excepcionales.

Desde una dimensión sociocultural, el espacio público es un lugar de relación y de identificación, de contacto entre las personas, de animación urbana, y a veces de expresión comunitaria. El espacio público es el espacio referencial muchas veces heredado, en consecuencia toda la ciudad existente, y por to tanto heredada, es toda ella ciudad histórica.

En la ciudad tradicional, histórica [...] la memoria urbana es bastante fácil de definir. Es la imagen que permite a los ciudadanos identificarse con su pasado y presente como una entidad cultural, politica y social. Los espacios privilegiados de los monumentos como marcas en el tejido de la ciudad [...] [9]

La dinámica propia de la cludad y los comportamientos de la gente pueden crear espacios públicos que juridicamente no lo son, a que no estaban previstos como tales, abiertos o cerrados, de paso o a los que hay que ir expresamente. Una fábrica o un depósito abandonado o un espacio intersticial entre edificaciones pueden devenir espacio público, Lo son 
casi siempre los accesos a estaciones y puntos internodales de transporte, los entornos de algunos grandes equipamientos (hospitales, universidades, etc.) y a veces las reservas de suelo para una obra pública o de protección ecológica. En cualquier caso lo que define la naturaleza del espacio público es el uso y no el estatuto juridico.

Lo que no funciona es el intento de marcaje de nuevos espacios instrumentaies a los que se intenta dar una nueva simbología por medio de la privatización de espacios públicos[...]; es decir, la idea de crear unos espacios que reproducen funciones de centralidad urbana, que tratan de reconstruir, y reconstruyen, a veces con bastante éxito la densidad de la vida urbana pero que privatizan y a la vez que privatizan, sesgan definitivamente los usos y la percepción de este espacio porque está dominado por la función comercial. No hay nada de malo en la función comercial, una función tan legitima como cualquier otra en la sociedad. Pero, la cuestión es la estructuración simbólica sobre la base de la predominancia excesiva de esta función. [10]

En ocasiones los procedimientos jurídicos burocráticos han llevado a considerar que el espacio público ideal es el que está prácticamente vacio, donde no se puede hacer nada. Y, la excesiva protección impide el uso, por ejemplo cuando con las mejores intenciones se peatonalizan radicalmente a núcleos centrados o se prohibe todo tipo de actividades o servicios comerciales en plazaso parques.

En otras ocasiones, el funcionalismo predominante en el que se basa el urbanismo moderno descalificó pronto el espacio público al asignarle usos especificos. En unos casos se lo confundió con la vialidad o con retales verdes.

En otros se lo sometió a las necesidades del "orden público" (es decir espacios apropiados para la intervención de la policia - el ejército). En casos más afortunados se priorizó la monumentalidad, el "embellecimiento urbano" o se lo vinculó 
a la actividad comercial. En los menos afortunados se utilizó como mecanismo de segregación social, bien para excluir, bien para concentrar (por medio, por ejemplo, de la accesibilidad o de la falta de ella).

El espacio público supone pues dominio público, uso social colectivo y multifuncionalidad. Se caracteriza fisicamente por su accesibilidad, lo que lo convierte en un factor de centralidad. La calidad del espacio público se podrá evaluar sobre todo por la intensidad y la calidad de las relaciones sociales que facilita, por su capacidad para generar mixturas de grupos y comportamientos; por su cualidad de estimular la identificación simbólica, la expresión y la integración cultural. Por ello, es necesario que el espacio público se piense como obra de cualificación del entorno $y$ de calidad intrinseca como son la continuidad en el espacio urbano y la facultad ordenadora del mismo, la generosidad de sus formas, de su diseño y de sus materiales y la adaptabilidad a usos diversos a través del tiempo.

\section{Sobre los efectos perversos del funcionalismo.}

El urbanismo contemporáneo, heredero del movimiento moderno fue reconstructor de ciudades después de la Segunda Guerra Mundial. Se orientó hacia un funcionalismo eficiente, dotado de un instrumental separador más que integrador, (la zonificación, los modelos), justificado por urgencias sociales (vivienda, equipamientos básicos) y acentuado por la compartimentación de las administraciones públicas y de los cuerpos profesionales (por ejemplo el dominio de los ingenieros en la planificación de los transportes, sin el complemento de otras disciplinas). El resultado ha sido casi siempre la aplicación de politicas sectoriales en lugar de realizar actuaciones que articulen la diversidad y la complejidad de las demandas urbanas. Asi resultaron las grandes operaciones de vivienda donde cada operación se destinaba a un segmento social determinado y la prioridad era asignada casi siempre a la vialidad como ordenamiento y como inversión. De esta manera el espacio público pasó a ser un elemento residual.

Pese a todo, el movimiento moderno no era tan simplista como el urbanismo funcionalista del capitalismo desarrollista de los 50 hasta

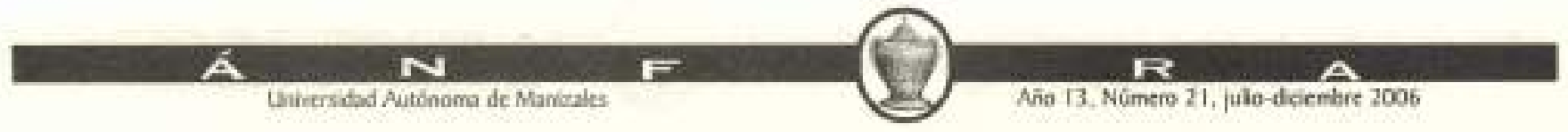


hoy. Su preocupación por la vivienda masiva, la higiene social y el paisaje urbano, la importancia acordada a las comunicaciones expresaba una visión productivista, no especulativa de la cludad y un interés por las condiciones de vida de las poblaciones trabajadoras. Sus propuestas urbanas podian ser interesantes tamblén por su complejidad, por la capacidad de integrar objetivos sociales, ambientalistas y estéticos. Ejemplos de ello serian el Plan Maciả (o Le Corbusier) para Barcelona en 1932, contemporáneo del Regional Planning y al que siguieron la casa-bloc y la municipalización del suelo urbano.

Pero el urbanismo funcionalista que ha predominado en España entre los 60 y 70 y en América Latina en las últimas décadas ha tenido que pagar el precio de sus limitaciones y el de los usos perversos que se ha hecho de él. La combinación del monofuncionalismo de los programas y de sectorización de las politicas públicas con las dinámicas del mercado en ciudades clasistas, agravadas por las rentas de posición, cada vez mas polarizadas, de los "instalados" respecto a los "aliegados" (inmigrados), ha dado lugar situaciones urbanas insoportables. Grupos residenciales que se degradan rápidamente por su mala calidad, por la falta de inserción urbana, por su anomia sociocultural, por la pobreza de los equipamientos. Áreas centrales congestionadas y especializadas que pierden su rol integrador en beneficio de funciones administrativas. Barrios históricos despedazados y desarticulados por actuaciones viarias poco respetuosas con los entornos y con la calidad de la vida cotidiana de los residentes.

Diseminación en el territorio metropolitano de centros comerciales, campus universitarios e industrias que ordenan la vida de la población activa según la tríada sarcástica del '68: "Metro, boulot, dodo" (Metro, trabajo, dormir). Procesos de desvalorizaciónvalorización inmobiliaria que provocan el despiazamiento de los antiguos pobladores de áreas degradadas y casi siempre céntricas; ahora "recuperadas" por los sectores altos, con la consiguiente pérdida del derecho a la centralidad y a la accesibilidad para los más desfavorecidos socialmente. Es decir, intervenciones que potencian el círculo vicioso de la marginación física y social.

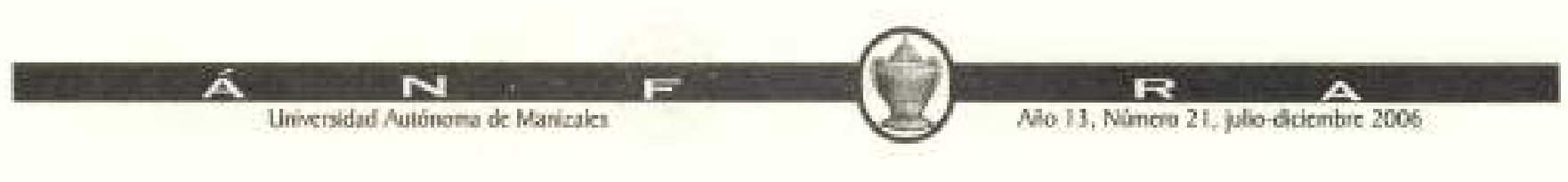




\section{4. ¿Réquiem para la ciudad?}

Como hemos dicho en capitulos anteriores la ciudad actual, la ciudad de la $3^{\circ}$ revolución, esta hecha de superposiciones, de múltiples situaciones. Por otro lado; la ciudad que hemos forjado en nuestro imaginario y consolidado como un valor y una conquista es un producto físico, politico y culturalmente complejo, europeo y mediterráneo, americano y asiático, caracterizado como concentración de población y de actividades. Un lugar que propicia la mezcla social y funcional, con capacidad de autogobierno y que es ámbito de identificación simbólica y de participación civica. Ciudad como lugar de encuentro, de intercambio. Ciudad como cultura y comercio. Ciudad de lugares y no únicamente espacio de flujos.

Parece entonces dificil renunciar a estas bondades urbanas. Es este conjunto de valorizaciones la raiz de una "contra-acción" respecto al discurso de "la muerte de la ciudad". Se recuperan los centros urbanos y se atribuye valor de centralidad a viejos barrios populares. Aunque, como efecto perverso, en muchas de estas intervenciones se produce una nueva especialización (cultural, turistica, comercial) de los centros urbanos y una "gentrificación" de residentes y usuarios. Pero, una política urbana activa $y$ permanente $y$ una gestión descentralizada puede limitar estos procesos y mantener áreas de carácter popular al igual El siglo XX ha sido calificado no solamente como el siglo de las ciudades, sino también como el de su muerte desde que asi lo escribiera Jane Jacobs [11] y más recientemente Françoise Choay [12], han aparecido infinidad de libros sobre esta muerte anunciada [13]. Pero a pesar de todo, vemos como las luces vuelven a la ciudad (Turn up the lights, portada de The Economist, 1995), precisamente por el éxito de las politicas basadas en el espacio público. Es la consideración de la ciudad como espacio público la que revive la esperanza de la cludad como lugar.

Volviendo entonces a la pregunta recurrente ¿Ha muerto la ciudad? ¿Está en crisis? ¿La ciudad de la calle y de la plaza, del espacio público y civico, la ciudad abierta, de mezclas y contactos es un residuo del pasado objeto de melancolia de urbanistas maduros? 
Existe una respuesta colectiva que se presenta regularmente en la historia de la ciudad y del urbanismo cuando las formas del crecimiento urbano o la evolución de la ciudad existente da prioridad a la edificación y / o a la vialidad, cuando los espacios se especializan debido a la segregación social o a la zonificación funcional, cuando la ciudad pierde cualidad de auto representación. Es una reacción social y cultural de retorno al espacio público que a menudo mezcla el "passeisme" [14] y la modernidad, la mitificación del pasado y una propuesta de sintesis para el futuro, demanda local y valores universales. Pese a sus limitaciones es una reacción oportuna y necesaria para evitar el desastre urbano que supone confundir ciudad con urbanización.

Otra manera de minimizar y enfrentarnos a la pregunta sobre la muerte de las ciudades es argumentar que en la historia de las ciudades se han vivido cambios por lo menos tan aparatosos como los actuales. A veces aún mayores; por ejemplo el tránsito de la ciudad amurallada a los ensanches modernos, o a la ciudad metropolitana, con sus suburbios y su estructura politica plurimunicipal, estimulada por el desarrollo del transporte masivo y del uso del automóvil. Incluso podria aducirse que estamos simplemente presenciando una nueva fase del crecimiento metropolitano.

Por otra parte, es inevitable reconocer su razón a los historiadores cuando critican el simplismo de reducir la historia urbana a tres grandes etapas o edades. La primera, de la cludad concentrada, separada de su entorno. La segunda, la de la ciudad metropolitana, ciudad más periferia. $Y$, la tercera que es la ciudad actual, la de la ciudad "a repensar" en la globalización. La ciudad-región, la ciudadred, multipolar o policéntrica, inserta en sistemas urbanos macroregionales, ejes continentales y flujos globales. Sin embargo, esta distinción es útil a los urbanistas ya que permite focalizar la atención en las nuevas dinámicas, no como una maldición fatal o como la expresión objetiva de la modernidad, sino como un desafio al que se debe responder. Descubrir los elementos de continuidad posibles respecto al pasado y distinguir lo necesario de lo excesivo o evitable en los nuevos procesos, es una condición para enfrentarnos a este reto junto con la propuesta de nuevos modelos y proyectos que

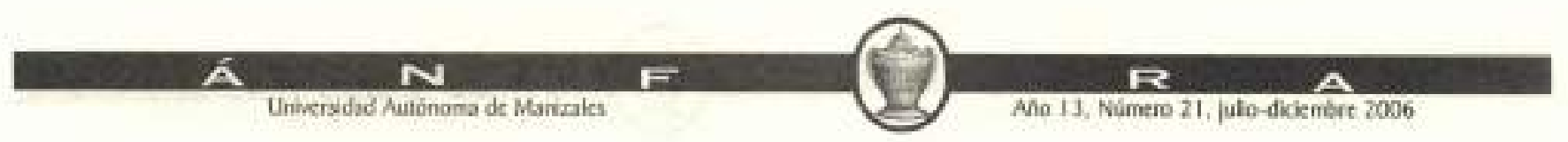


formulen respuestas integradoras.

Creemos, por lo tanto, que hace falta analizar las nuevas dinámicas urbanas y elaborar respuestas a los desafios que nos planteamos desde la perspectiva del espacio público y de la relación entre su configuración y el ejercicio de la ciudadania, entendida como el estatuto igualitario que permita ejercer un conjunto de derechos y deberes civicos, politicos y sociales.

El espacio público nos interesa principalmente por dos razones. En primer lugar porque es donde se manifiesta, con mayor fuerza y mayor frecuencia la crisis de "cludad" y de "urbanidad". Por lo tanto, es un punto sensible para actuar si se pretende impulsar politicas de "hacer ciudad en la ciudad".

En segundo lugar, porque las nuevas realidades urbanas, especialmente las que se dan en los márgenes de la ciudad existente, plantean unos retos novedosos al espacio público: la movilidad individual generalizada, la multiplicación y la especialización de las "nuevas centralidades" y la fuerza de las distancias que parecen imponerse a los intentos de dar continuidad formal y simbólica a los espacios públicos. La dialéctica movilidades centralidades es una cuestión clave del urbanismo moderno y la concepción de los espacios públicos es, a su vez, un factor decisivo, aunque no sea el único, en el tipo de respuesta que es necesario dar.

\section{Los movimientos ciudadanos y la crítica urbana en la construcción de la ciudad.}

En los años 60 y 70 la conflictividad urbana irrumpió con fuerza en la vida politica y social de la mayoria de los paises de Europa y América. Los movimientos sociales de los sectores populares y medios emergieron en la politica local democrática con sus críticas $y$ reivindicaciones urbanas. Las movilizaciones ciudadanas y de barrio tienen antecedentes en la mayoria de las ciudades europeas y se expresaban en la lucha por la vivienda, por el precio de los transportes, por los servicios urbanos básicos, por plazas y jardines, por centros culturales y equipamientos sociales y deportivos. 
También, se oponian a las expropiaciones, la corrupción, el autoritarismo y la opacidad de las decisiones de la politica urbana. Estos movimientos sociales urbanos surgieron aún en contextos dictatoriales, como en la España de los años setenta, y a menudo paralizaron actuaciones y proyectos, pudiendo negociar compromisos que satisfacian algunas de las reivindicaciones urbanas sobre vivienda, expulsiones, accesos, equiparnientos o transporte. Fue a partir de estas situaciones que el "usuario", el ciudadano, se convirtió en interlocutor real para los proyectos urbanos y arquitectónicos, dejando de ser una pobiación abstracta. En aigunos casos se llegaban a negociar programas de vivienda pública, servicios y espacio público para calificar áreas marginales o con deficiencias.

El espacio público de la calle nunca ha sido pre-otorgado [... ] ha sido siempre el resultado de una demanda social, negociación y conquista... los espacios públicos tienen que adaptarse a diferentes públicos... [15].

A las reacciones de carácter social se añadieron otras de carácter cultural y politico, Los herederos del movimiento moderno y otros profesionales e intelectuales del urbanismo, de la arquitectura y de otras disciplinas se unieron por una preocupación cultural, social y estética respecto a la ciudad y levantaron su voz contra los excesos del urbanismo desarrollista y funcionalista. En ciertas ocasiones prevaleció la revalorización formal de la ciudad existente o la mitificación culturalista de la ciudad histórica. Otras veces, se reforzó la defensa del ambiente urbano y se reivindicó el desarrollo de un urbanismo "austero" frente al despilfarro. La critica social acompañaba, por descontado, muchos de estos reclamos.

La crítica política a este urbanismo de la zonificación y del desarrollismo recogia algunas o muchas de las criticas sociales y culturales, que apoyados en estos movimientos aportaron un plus contra el autoritarismo tecnocrático o corrupto, contra el sometimiento de las politicas públicas a grupos de intereses privados, y a favor de la transparencia y la participación ciudadana, la revalorización de la gestión politica local y la descentralización. En esta critica politica coincidieron los movimientos sociales urbanos, las 
posiciones críticas de carácter ideológico o cultural y las fuerzas politicas más democráticas o progresistas, aunque también hay que decir que las direcciones politicas partidarias tardaron en "descubrir" el potencial político de las problemáticas urbanas.

La Influencia de la critica ciudadana sobre el urbanismo ha dejado siempre un saido positivo en la ciudad. En los últimos diez años estas reivindicaciones y propuestas han actuado como impuiso de la revalorización de los centros históricos, han apostado a la superación de un urbanismo concebido como vivienda más vialidad $y$ han fomentado la incorporación de objetivos de construcción social y de calificación ambiental. La importancia acordada a los espacio públicos como elemento ordenador y constructor de la ciudad fue muchas veces concebida antes por estos movimientos criticos ciudadanos que por otros colectivos incluidos quienes debian proyectarlos.

Sin embargo, a veces las reacciones barriales son contrarias a los cambios y transformaciones. Se olvida que "el barrio" forma parte de un todo, que los otros usuarios, aquellos que trabajan, consumen o lo atraviesan, también tienen interés y derecho a esta parte de la ciudad. En otros casos, el "conservacionismo" proviene de ciertos sectores de la cultura urbana que consideran intocable cada piedra y cada forma que tenga una edad respetable. Pero, hay que recordar que no hay preservación urbana sin intervención transformadora que contrarreste las dinámicas degenerativas.

Por otra parte, los proyectos desarrollistas de los años 60 y 70 constituyen la raiz de cierta desconfianza de los movimientos urbanos más críticos hacia los grandes proyectos urbanos. Estas experiencias nefastas contaminadas de corrupciones, especulaciones, impactos depredadores sobre el medio ambiente urbano, se tradujeron en pérdida de espacios públicos, despilfarro, proyectos fragmentados y excluyentes. En todo caso, la transparencia, la información y la apertura de los gestores hacia el debate permanente deben ayudar a generar legitimidad y alternativas, ya que no siempre lo "small is beautiful". Y los grandes proyectos no sólo son necesarios sino que requieren amplio consenso social. 
Hoy en dia el conflicto urbano se expresa tanto en los centros como en las periferias. Las tomas okupas [16] en los corazones de las ciudades europeas plantean nuevas estrategias para viejos temas y renuevan las preguntas sobre la propiedad y el uso colectivo de los espacios, alli donde todo parecia ya consolidado. En las periferias de las grandes ciudades latinoamericanas también aparecen nuevas dinámicas de ocupación del territorio en forma de asentamientos que con la organización y la autogestión tratan de construir ciudad y no sólo viviendas precarias.

Entre las contribuciones más importantes de los movimientos ciudadanos de los últimos 30 años hacia la gestión de la ciudad y al urbanismo de este final de siglo, citaremos tres:

1. La revalorización del "lugar", del espacio público, del ambiente urbano, de la calidad de vida, de la dialéctica barrio-ciudad y del policentrismo de la ciudad moderna.

2. La exigencia de la democracia ciudadana, de la concertación y de la participación en los planes y proyectos, de programas integrados, la gestión de proximidad y la recuperación del protagonismo de los gobiernos locales en la politica urbana.

$Y$, 3. como consecuencia de lo anteriormente dicho, o tal vez como premisa, la recreación del concepto de ciudadano como sujeto de la política urbana, quien "se hace" ciudadano interviniendo en la construcción y gestión de la ciudad. El marginal se integra, el usuario ejerce derechos, el residente modela su entorno.

Todos adquieren autoestima y dignidad aceptando y respondiendo a los desafios que les plantean las dinámicas y las politicas urbanas.

\section{El urbanismo del espacio público.}

El urbanismo del siglo XIX formalizó la distinción juridica entre espacio privado y espacio público, regulando los usos edificatorios, públicos y privados con el fin de garantizar los espacios públicos y la diversidad de funciones $y$ de usos colectivos que alli se podrian 
desarroliar. A finales del siglo la necesidad de intervenir sobre la ciudad industrial, ya sea para renovarla o para extenderla dio lugar a politicas urbanas activas para hacer espacio público. Dos figuras del urbanismo de la segunda mitad del XIX, Haussmann y Cerdà, uno reestructurando el viejo Paris y el otro diseñando la Barcelona moderna del Ensanche, ordenaron la ciudad alrededor de los espacios públicos, elemento principal tanto del sistema de avenidas, plazas y monumentos de Haussmann, como de la trama cuadriculada de Cerdà. Es asi como la tradición urbanistica que heredamos no hace del espacio público un elemento especializado y refugio de peatones en un tejido urbano concebido como suma de edificios y vias para vehículos, sino que lo identifica y lo concibe como la forma misma de la ciudad, y por lo tanto está presente en toda ella.

Luego, a lo largo del siglo XX, la combinación de diversos factores tales como: la dinámica de la propiedad privada, la prioridad pública y privada a los programas inmobiliarios, la ocupación exclusiva del espacio "circulatorio" por parte del automóvil, la oferta comercial cerrada, la inseguridad cludadana, etc. condujeron a la crisis del espacio público urbano. En consecuencia, para "saivar" o recuperar el espacio público se reforzó la tendencia a convertirlo en un elemento especializado, un "equipamiento" más de la ciudad. Es asi como comenzaron a extenderse los espacios segregados y monovalentes. Un espacio para nifios, otro para perros, otro para aparcar, otro "monumental", etc.

Con esto el espacio público pierde sus dos funciones "fundacionales", de las cuales derivan todas sus potencialidades:

1 - Dar forma y sentido al conjunto de la ciudad, garantizar trayectos y elementos de continuidad y resaltar las diferencias entre edificios, manzanas y áreas urbanas.

2- Ordenar las relaciones entre edificios, equipamientos, monumentos, solares, vias, espacios de transición y espacios abiertos en cada área de la ciudad.

Es decir funciones que se sitúan en dos escalas diferentes. 
Comprender las diferentes lógicas urbanas para la creación de tejidos compatibles con las disposiciones corrientes de las ciudades, y con lo que sabemos de la práctica, que se pueden relacionar (...) es decir susceptibles de acoger las formas arquitectónicas heredadas del movimiento moderno, [...] también aquellas que no entran en lo que consideramos cultura arquitectónica, [17]

Evidentemente el espacio público se materializa en avenidas y calles, plazas y parques, equipamientos abiertos o cerrados. Pero su funcionalidad urbanistica es ordenadora de flujos, es relacional.

La recuperación de la cultura del espacio público es hoy una respuesta no solamente a los déficits de espacio y equipamientos de uso colectivo, sino también a la concepción "especializada" del espacio público. Esta concepción ha sido reforzada en los últimos años por un "urbanismo de productos" reduciendo el concepto de proyecto urbano, que antes que producto construido debe definir los entornos y las condiciones de la edificación. La arquitectura urbana puede ser muy interesante pero no es lo mismo que el urbanismo y el proyecto urbano. El urbanismo de productos, vinculado a estrategias de competitividad y a una cierta sumisión a la iniciativa privada, a menudo contribuye a la fragmentación y a la segregación urbana. Pero orientado por los poderes públicos podría convertirse en un factor de construcción de una lógica de ciudad que partiendo de la fragmentación fuera capaz de reducirla, en lugar de acentuarla como generalmente sucede. [18]

Esta tendencia al urbanismo de productos se justifica no sólo por el negocio privado. También para reducir el riesgo, tanto el riesgo de la inversión como el del encuentro con el otro, el riesgo de la diferencia y la heterogeneidad. La seguridad pasa a ser el único horizonte deseado y se vuelve sinónimo de homogeneidad, transformando la ciudad en una maqueta, en un no lugar.

Desde la moda de una cuitura urbanistica débil o pobre las ciudades del cambio de siglo, incluyendo las más recientes inversiones en la construcción de edificios para centros comerciales suburbanos y parques temáticos, downtown festival market y espacios temáticos, 
se puede identificar una continua búsqueda de entretenimiento de masas sin riesgo, que minimicen el contacto entre ricos y pobres, entre blancos y negros, a la vez que se maximizan los beneficios financieros de los promotores.

De acuerdo con Herbet Muschamp [19], esta clase de negocios urbanos busca reinscribir la seguridad de los valores de la clase media en el centro urbano. Un cierto hibrido, una ética urbano-suburbano que fusione la seguridad del suburbio y la estandarización con la congestión urbana, ofreciendo a la clase media un agradable espacio público donde la gente pueda disfrutar sin tener miedo. Pero esta clase de negocios urbanos fuerza a la ciudad a convertirse en una fortaleza invisible donde ricos y pobres continúan polarizados pero la distancia es menos obvia. [20]

Existe otra concepción de la ciudad que asume y aprueba el caos metropolitano y de la ciudad sin lugar. Asi la ciudad "genérica" de Koolhaas fabrica piezas dispersas en el territorio, exalta la anomia y presupone que del caos saldrá el mejor orden posible. Se trata de un pensamiento urbanistico funcional para los negocios privados, los politicos con prisas y los arquitectos gestuales.

La ciudad genérica es la ciudad liberada de la esclavitud del centro, de la camisa de fuerza de la identidad. Tiene el sentido de hoy y surge de las reflexiones de les necesidades de hoy. Es la ciudad sin historia.

La serenidad de la ciudad genérica se cumple a través de la evacuación de la esfera pública [...] En las programaciones urbanas ahora encontramos sólo lugar para los movimientos necesarios, esencialmente aquellos del automóvil [...] Su principal atractivo es la anomia.

La calle ha muerto $[\ldots][21]$

La ciudad como lugar productor de ciudadanía ámbito de ejercicio de la misma, no es la ciudad genérica con tendencia a la anomia, privatizada por los miedos y la insolidaridad, orientada socialmente por los valores individualistas y "familiaristas" [22] (es decir buscar 
solamente la compañía y la proximidad de los "idénticos"), fragmentada a la vez por las estructuras fisicas y administrativas del territorio y por localismos corporativos de guetos de todo tipo, $\sin$ referencias físicas y simbólicas comunes y con sentido para el conjunto de sus habitantes.

Por mucho que se pretenda justificar la ciudad genérica, la ciudad caos, la ciudad emergente en las periferias o la telépolis por la gran heterogeneidad de la sociedad post-industrial, por la dinámica propia del mercado o por el impacto determinante de las nuevas tecnologias de comunicación, el hecho es que estos factores pueden ser útiles o regulables con finalidades muy diversas, pueden actuar en direcciones muy opuestas, según los valores y objetivos de las políticas públicas.

En este sentido, la ciudad del espacio público pretende construir tejidos urbanos con vocación igualitaria y abierta, con elementos referenciales productores de sentido, con diversidad de centralidades y con capacidad de articular piezas y funciones diferentes. En los espacios públicos se tiene que producir un equilibrio de funciones entre lo público y lo privado. Desde lo público se deciden la densidad, los usos y el diseño urbano, Y lo privado lo desarrolla, cede suelo y construye. En esta concepción importa más la calle que la casa.

\section{La ciudad es la gente en la calle.}

¿Qué es un puente? Preguntaba el falsamente ingenuo Julio Cortázar. $Y$ se respondia: una persona atravesando el puente. ¿Qué es una ciudad? Un lugar con mucha gente que interactúa cara a cara. Un espacio público, abierto y protegido. Un lugar como hecho material y social, productor de sentido. Una concentración de puntos de encuentros. En la ciudad to primero son las calles y plazas, los espacios colectivos, sólo después vendrán los edificios y las vias que son los espacios circulatorios.

El espacio público define la calidad de la ciudad, porque indica la calidad de vida de la gente y la calidad de la ciudadanía de sus habitantes. Allan Jacobs en su excelente libro, Greats streets [23] , 
analiza las ciudades a partir de la calidad estética y cultural, funcional y social, simbólica y moderna de sus calles. Entre los diez primeros ejemplos del libro se incluyen dos avenidas de Barcelona, las Ramblas y el Paseo de Gracia, sin embargo un barcelonés no puede olvidar que en los años 60 , el llamado urbanismo desarrollista estuvo a punto de hacer desaparecer estos paseos urbanos en beneficio de las vias rápidas de circulación a lo que la ciudadanía resistió, luego las tendencias de los años 80 nos llevaron nuevamente a la cultura de la cuadricula y a Cerdà, quien escribió: "en la ciudad las calles no son únicamente carreteras". Hoy, la calle se encuentra nuevamente en alza $y$ es objeto de un recuerdo romántico al considerario un anacronismo. Se admite con demasiada facilidad su inevitable substitución por vias más o menos rápidas y por edificios altos y aislados. O bien, es víctima de una sobreprotección y se la segrega de la circulación mecánica, se convierte en paseo acotado. $Y_{\text {, }}$ a la vez pierde su rol de lugar de paso, de trayecto, de elemento de continuidad y de relación entre las piezas urbanas. Es así como deviene un producto, uno más.

Nuevamente hemos de señalar que fue Idelfons Cerdà quien recordó que la complejidad de la calle se tiene que considerar en una dimensión que vaya mucho más allá de su componente circulatorio:

... por qué medios la calle, sin dejar de ser vía pública urbana, sin perjuicio de los servicios que como tal debe prestar, puede y debe atender a otros que de ella exigen, los vecinos por un lado y los transeúntes por otro, respondiendo a la vez a las exigencias de la locomoción y al organismo social y urbano... la calle sin perder $5 u$ carácter de "carretera", está destinada a prestar, y realmente presta una serie interminable de servicios a cual más importante al vecindario estante... En cuanto a la amplitud del conjunto de fajas y zonas destinadas al movimiento pedestre, después de meditar muy detenidamente sobre esta cuestión, resulta que por ningún concepto debe ser menor de la concedida al movimiento ecuestre y rodado... Esas superficies que en cada encrucijada quedan vacias y al parecer sin objeto, después de dejar plenamente atendidas las exigencias de circulación, ofrecen a los vendedores callejeros de comestibles y otros artículos de uso común y frecuente, puestos a propósito para 
atender su utilisima industria... [24]

Separar no es segregar. En la ciudad, para hacer ciudad, no conviene aislar las calles. Puede haber áreas y calles peatonales pero no deben contribuir a la marginalidad o al "museismo" urbano. Las calles tienen que ser accesibles también para los vehiculos y son precisas vias anchas para atravesar la ciudad. Pero otras pueden priorizar su función de paseo o bulevar, lugar de estar o de pasar lenta, tranquilamente. Las calles han de encontrar formas no rigidas de separación de las funciones como pueden ser los escalones, el mobiliario urbano, las hileras de árboles, etc. Las vias segregadas, como las rondas en Barcelona, el boulevard periférico en París o las autopistas en Nueva York, no sólo tienen que ser la excepción sino que es necesario hacerlas lo más urbanas posible. Es decir, insertas e integradas en el tejido urbano por su función y por su diseño.

Un adecuado tratamiento de las calles y vias urbanas supone tener criterios para distinguir y tratar de forma diferente las calles ordinarias, pasajes, calles mayores o ramblas, bulevares o avenidas, autovias urbanas 0 autopistas.

Siempre, es necesario garantizar la polivalencia de uso como espacio público y su accesibilidad articulándola con la red viaria de la ciudad. Lo cual también es válido para las plazas, los entornos o espacios de transición vinculados a grandes equipamientos y parques urbanos.

En cuanto a las infraestructuras, éstas generalmente han sido consideradas agresiones inevitables al espacio público ciudadano o no han estado tratadas para otros usos que el especifico de su función: redes de servicios (energia, agua, teléfono, etc.). infraestructuras y sistemas de transporte colectivo (desde las estaciones hasta las paradas da autobús). Es interesante ver el tratamiento y reconversión de áreas ferroviarias, puertos, canales y viaductos, cuarteles e industrias obsoletas que se realiza actualmente. Este tipo de intervenciones se deben de extender tambièn a los accidentes topográficos. Es necesario ver en estos elementos oportunidades y no obstáculos para el desarrollo de la ciudad y de la calidad de vida. [25] 
Por lo tanto, la cultura del espacio público nos lleva a considerar que todos los elementos que conforman el espacio físico urbano se pueden y se deben tratar con un uso polivalente y positivo, sacando ventajas y rendimientos en beneficio del espacio público.

\section{Espacio público y la forma de la ciudad.}

El hecho que el espacio público sea el elemento determinante de la forma de la ciudad ya es razón suficiente para atribuirle el rol ordenador del urbanismo y en primer lugar de la trama urbana.

La relación de la calle con la mezcla de usos ha dado lugar a la manzana o isla. Esta caracteriza la forma urbana de muchas ciudades europeas y americanas, y que en los casos de ciudades que han podido planificar su desarrollo ha dado lugar a formas regulares como la cuadricula. La trama cuadriculada es un ejemplo especialmente afortunado de mezclas de funciones y de usos, ya que permite la combinación de diferentes modos de circulación, de los peatones a los vehículos rápidos, crea espacios públicos de trayecto y de encuentro, donde se pueden instalar actividades efimeras o permanentes, establece una relación dinámica entre la calle y el espacio edificado y posibilita diferentes formas de espacios de transición, como explanadas, patios, manzana ablerta, pasajes, terrazas, porches y otros.

La trama urbana y el espacio público se condicionan mutuamente, y tienen que responder por tanto a concepciones compatibles. Obviamente otras formas distintas a la cuadricula y a la manzana son posibles y convenientes. Siempre que se evalúen los efectos que estas formas, por ejemplo los poligonos, los edificios altos discontinuos, etc. tendrán sobre el sistema de espacios públicos y se corrijan o reduzcan los eventuales efectos perversos que puedan provocar.

Otros elementos de la forma urbana que condicionan los espacios públicos son los grandes ejes, las grandes plazas y los parques urbanos que a menudo son productos de la historia urbana pero también de decisiones urbanisticas relativamente recientes que no 
siempre tienen en cuenta los impactos sobre la trama y los espacios públicos del entorno. Es decir que pueden tanto unir como separar, ser un importante elemento de animación urbana como crear desierto a su alrededor o ser ellos mismos un desierto. Los monumentos que generalmente se hallan situados en estos espacios son elementos de referencia, que marcan diferencias o atribuyen identidad, es decir significantes, pero su exceso lleva también a banalizar su significado.

También es necesario citar las grandes piezas especializadas como son los centros comerciales, las universidades y grandes equipamientos culturales, las áreas deportivas, los templos religiosos, las nuevas estaciones ferroviarias y otros. Estos equipamientos pueden generar espacio público nuevo o animar el que existe o todo lo contrario, pueden vaciarlo, introducir rupturas o soluciones de continuidad a la red urbana que debiliten el sistema de espacios públicos. En el punto anterior ya nos hemos referido a las infraestructuras de comunicación (vias rápidas, ferrocarriles) y la experiencia reciente demuestra que en vez de agresión al espacio público pueden ser un elemento cualificado del mismo (la ronda de Barcelona, el tranvia en muchas ciudades europeas, etc.)

Las grandes operaciones homogéneas de vivienda a menudo suman tres impactos negativos: homogenización social, segregación urbana y debilidad del espacio público.

Otro "producto urbano" son los parques de oficinas, empresariales o de centros administrativos que a pesar de las posibilidades que podrian ofrecer, muy frecuentemente niegan el espacio público ciudadano. Son necesarias normativas que introduzcan diversidad en los usos con viviendas, reservando las plantas bajas para bares y restaurantes, comercios y equipamientos culturales. Una perversión reciente del urbanismo es la introducción de edificios altos y aislados en tramas equilibradas, como la cuadricula, en nombre de la creación de espacio público cuando se trata de aparcamientos o de espacios exclusivos, a veces enrejados, que introducen rupturas en el espacio público preexistente. Por no hablar de los famosos parques temáticos, discutibles en ámbitos metropolitanos, y aberrantes en

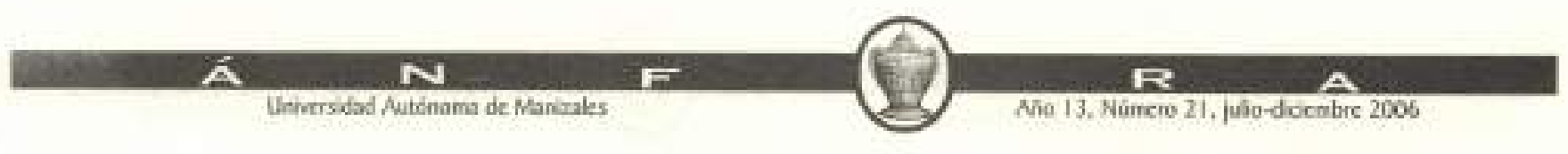


áreas urbanas densas.

Una consideración especial merecen, finalmente, los espacios de transición, es decir aquellos que se sitúan entre privados y públicos, 0 los generados por el impacto o el vacio de un equipamiento o una infraestructura sobre su entorno, o espacios residuales producidos por las formas del desarrollo urbano. Si vemos estos espacios como oportunidad nos daremos cuenta que en la ciudad actual las posibilidades de crear espacios públicos calificados 50 inmensas. Bien como espacios públicos permanentes, bien como oportunidad para el urbanismo "efimero".

El siglo XIX fue un siglo de destrucción - construcción de la ciudad como espacio público. Con perspectiva histórica podemos concluir que nos dejó en herencia una cierta sintesis entre Haussmann y Cerdà, que por momentos pareció que podría haber sido asumida y superada por el movimiento moderno para hacer la cludad a otra escala. ¿Podriamos concluir entonces que el siglo XX nos ha dejado una sintesis entre Sitte y Le Corbusier? LAcaso no se han acumulado las dicotomias entre el "passeismo" de Leon Krier y el Principe de Gales y la ciudad genérica de Rem Koolhaas $y$ la arquitectura de "productos"? ¿Hemos resuelto ya la ciudad del siglo XX para poder confrontarnos con los nuevos retos de la cludad del siglo XXI? Parece evidente que hoy más que de sintesis podemos hablar de una dialéctica de contrarios, entre dinámicas sociales y territoriales y entre culturas urbanisticas.

Es decir, hay que asumir los desafios de la ciudad de la sociedad de la información, dispersa e informacional, más regional que metropolitana, en tensión entre la desestructuración y la policentralidad, que hoy se extiende sobre las ruinas de la ciudad moderna y por las periferias. Asumir los desafios con intención de dar respuestas y con la modestia de darlas con incertidumbres, con audacia para experimentar y con humildad para admitir los errores.

La presión de la dispersión, la segregación y la segmentación del área urbana que se presenta como un magma indefinido nos obliga a redefinir los espacios públicos urbanos en las áreas de nuevos

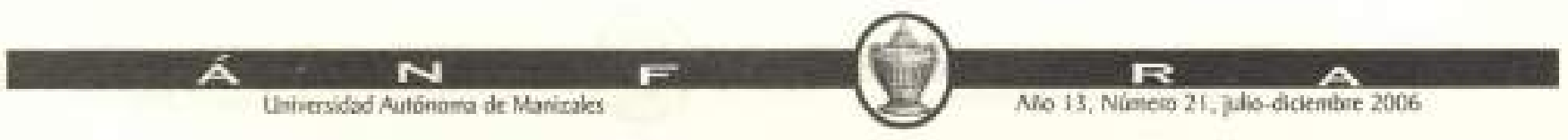


crecimientos. Es decir, recuperar la dimensión simbólica para identificar los espacios urbanos como referencias ciudadanas, hacer de los espacios de conexión o nodales, lugares con sentido, hitos civicos, atribuir a las áreas de nueva centralidad característiças del lugar central (monumentalidad, multifuncionalidad, intercambio, lugares de encuentro y de expresión). También es necesario mantener o hacer viviendas en las áreas con vocación terciaria, no excluir a la industria de las zonas residenciales, limitar y penalizar las operaciones que formalicen guetos para garantizar la polivalencia, la mezcla y la visibilidad de cada zona de la ciudad. A su vez estos valores y objetivos orientadores de las politicas urbanas deberian ser asumidos por los agentes sociales y económicos, públicos y privados, de manera que se garantizara el máximo de articulación entre los "productores de ciudad".

\section{Notas.}

[1] AUGE, M. (1994).

[2] SENNETT, R (1975)

[3] WIRTH, I. (1938-1962)

[4] SENNEIT, R. (1992)

[5] HABERMAS, J. (1993).

[6] LEFEBVRE, Henry (1968)

[7] BARCELLONA, P. (1992).

[8] LLARDI, M (1988) (1989),

[9] VIDLER, A. (1992).

[10] CASTELLS, M. ( 2001b)

[11] Jacobs, Jane (1961, 1967)

[12] Choay, Françoise (1994)

[13] Todo lo que es sólido se desvanece en el aire, argumenta Marshail Berman (1991). Es la dinámica objetiva del capitalismo, urbanicidad que necesita destruir para acumular, explica David Harvey (1996). Es la ciudad fragmentada de Jonathan Barnett (1996), la ciudad del Quartz, de las distopias y las pesadillas de Mike Davis (1990); la ciudad en los bordes como sumatoria de funciones interpretada por Joel Garreau en The Edge City (1991) o en la exposición del Instituto Francés de Arquitectura "Les entrées de la ville"(1997). La ciudad difusa o sin limites de Francesco Indovina 
(1991) o Michele Sernini (1996). La Metápolis de François Ascher (1995), quien probablemente sea el que mejor ha sintetizado la cuestión como una situación compleja que propone nuevas relaciones, nuevas formas que se suman y superponen a lo prexistente.

[14] Expresión francesa: recuperación de formas de arquitectura de las épocas pasadas

[15] LEES, L. (1998).

[16] BATISTA, A (2002)

[17] Panerai, Ph.; Mangin, D. (1999).

[18] Solà-Morales, M. (1984)(1997).

[19] Muschamp, H. (1995).

[20] Hannigan, ]. (1998).

[21] Koolhaas, R. (1997).

[22] Sennett, Richard (1975)

[23] Jacobs, Allan. (1993).

[24] Garcia Espuche, A.; Navas, T. (1999).

[25] HERCE, M.; MAGRINYA, F. (2002) 